\begin{tabular}{|c|l|}
\hline Title & $\begin{array}{l}\text { Effects of time and environmental conditions on the quality of DNA extracted from fecal samples for genoty ping of } \\
\text { wild deer in a warm temperate broad-leaved forest }\end{array}$ \\
\hline Author(s) & A getsuma Y anagihara, Y oshimi; Inoue, Eiji; A getsuma, Naoki \\
\hline Citation & $\begin{array}{l}\text { Mammal Research, 62(2), 201-207 } \\
\text { https://doi.org/10.1007/313364-016-0305-x }\end{array}$ \\
\hline Issue Date & 2017-04 \\
\hline Doc URL & http://hdl.handle.net/2115/68755 \\
\hline Rights & The original publication is available at www.springerlink.com \\
\hline Type & article (author version) \\
\hline File Information & Mammal Research.pdf \\
\hline
\end{tabular}

Instructions for use 
Mammal Research (2017) 62:201-207

DOI 10.1007/s13364-016-0305-x

\title{
Effects of time and environmental conditions on the quality of DNA extracted from fecal samples for genotyping of wild deer in a warm temperate broad-leaved forest
}

Yoshimi Agetsuma-Yanagihara $^{1} \&$ Eiji Inoue $^{2} \&$ Naoki Agetsuma $^{3}$

${ }^{1}$ Waku Doki Science Planning, 343-1 Hirai, Kozagawa, Wakayama 649-4563, Japan

${ }^{2}$ Department of Biology, Faculty of Science, Toho University, 2-2-1 Miyama, Funabashi, Chiba 2748510, Japan

${ }^{3}$ Wakayama Experimental Forest, Hokkaido University, 559 Hirai, Kozagawa, Wakayama 649-4563, Japan

Received: 8 September 2016 /Accepted: 23 December 2016 /Published online: 5 January 2017

\begin{abstract}
Extraction of DNA from non-invasive samples (feces) has been used increasingly in genetic research on wildlife. For effective and reliable genetic analyses, knowledge about which samples should be selected in the field is essential. For this reason, we examined the process of DNA degradation in feces of deer. We collected fresh fecal pellets from three wild deer living in a warm temperate forest. We then assessed the effects of time (3,5, and 10 days) under three environmental conditions (on the forest floor, on exposed ground, and inside the laboratory) on the rates of correct genotyping (CG), amplification failure (NA), genotyping error among positive amplification (ER), false alleles (FA), and allelic dropout (AD) of 15 microsatellite loci. The rate of CG significantly decreased, and those of NA and FA increased with increasing lapse of time. Rates of CG tended to be highest and those of NA, ER, FA, and AD to be lowest in feces kept inside, followed by those on the forest floor. Suitability of samples for DNA extraction was lowest in fecal pellets left on exposed ground, and we suspect that rain may hasten DNA degradation. NA rate could serve as a reliable indicator of the quality of fecal pellets because it was significantly positively correlated with ER rate. For efficient genetic analyses using deer feces in warm temperate zones, we recommend collecting fecal pellets within 3 days of defecation, during periods without rainfall and from under the cover of trees.
\end{abstract}

Keywords Amplification failure, Cervus nippon yakushimae, DNA degradation, Genotyping error, Microsatellite, Non-invasive sampling. 


\section{Introduction}

Fecal samples have been used increasingly as a source of DNA for genetic research on elusive animals (Kohn and Wayne 1997; Brinkman et al. 2010; Inoue 2015). Their use can avoid negative impacts on wildlife conservation and animal welfare that more invasive sampling methods often have. In addition, non-invasive genetic sampling methods such as fecal sampling greatly increase the potential of socioecological research, e.g., in estimating population sizes or analyzing the relationship between social behaviors and kinship (Bellemain et al. 2005; Inoue et al. 2008; Beja-Pereira et al. 2009; Inoue et al. 2013; Lampa et al. 2013).

As demonstrated by Beja-Pereira et al. (2009), field conditions, sample storage methods, and DNA extraction protocols are very important for reliable genotyping using DNA from feces, because the quantity and quality of the subject animal's DNA in feces tend to be low. Furthermore, DNA degradation in feces increases with time after defecation, ambient temperature, humidity, and rainfall (Lucchini et al. 2002; Hajkova et al. 2006; Brinkman et al. 2010; Wedrowicz et al. 2013). Consequently, careful selection of fecal samples in the field is important for effective and reliable genetic analysis, and knowledge of the DNA degradation process is useful for selecting feces in the field for genetic research. These processes have been examined in a limited range of species and habitats as follows: wolf, Canis lupus (Lucchini et al. 2002); brush-tailed rock-wallaby, Petrogale penicillata, and red fox, Vulpes vulpes (Piggott 2004); otter, Lutra lutra (Hajkova et al. 2006); brown bear, Ursus arctos (Murphy et al. 2007); blacktailed deer, Odocoileus hemionus (Brinkman et al. 2010); koala, Phascolarctos cinereus (Wedrowicz et al. 2013); pygmy rabbit, Brachylagus idahoensis (DeMay et al. 2013); and Sonoran pronghorn, Antilocapra americana (Woodruff et al. 2015). With continuing growth in the use of fecal samples in research, there is a need for more information to be gathered on additional species in various types of habitat. In addition, although the appearance of fecal surface texture may provide important cues for feces selection, changes in the appearance of fecal texture over time and their relationship to DNA degradation have not been well documented. The relationship between DNA degradation and the surface texture of feces needs to be examined.

For wild ungulate species, most genetic research so far has relied on tissue samples from hunted individuals (Tamate et al. 1998; Tamate et al. 2000; Schettler et al. 2006; Yamada et al. 2007; Yuasa 2007; Yuasa et al. 2007; Henry-Roitberg 2008; Pérez-Espona et al. 2009; Barbosa and Carranza 2010). This may be because large numbers of tissue samples could be easily obtained from hunters of common game species and pest species (Brinkman et al. 2010). However, hunting is not always feasible for 
collecting DNA samples of ungulates living in severe topography and/or at low population density. Moreover, hunting may be prohibited if the species is endangered or living in a wildlife protection area, even though genetic research on such populations should be a priority for their conservation.

Consequently, non-invasive genetic research has gradually begun to prevail even for ungulate species as follows: reindeer, Rangifer tarandus (Flagstad et al. 1999); bighorn sheep, Ovis canadensis (Wehausen et al. 2004); wild ass, Equus hemionus (Renan et al. 2012); and Cephalophus spp. (Akomo-

Okoue et al. 2015). However, the process of DNA degradation in ungulate feces has been examined only in two species: black-tailed deer in a coniferous forest in Alaska (Brinkman et al. 2010) and Sonoran pronghorn in an arid area of Arizona (Woodruff et al. 2015). No other information is available for ungulate species, even though they are distributed in a wide variety of habitats from tropical to polar zones (Whitehead 1993). Therefore, there is a distinct need for more information on the DNA degradation process and for recommendations on how to select feces for DNA analysis for a wider range of ungulate species living in various habitats.

In this study, we surveyed the process of DNA degradation in the feces of Yaku sika deer (Cervus nippon yakushimae), a subspecies of the Japanese sika deer (Cervus nippon), inhabiting a warm temperate evergreen broad-leaved forest in Yakushima, southern Japan. We examined the effects of time after defecation and ambient conditions (under cover of the forest canopy, on exposed ground, and in the laboratory) on the success of genotyping using 15 microsatellite markers in deer feces. We also report changes in the appearance of the fecal pellets over time. Finally, we make recommendations for the collection of deer feces in warm temperate zones for efficient and reliable genetic analyses.

\section{Materials and methods}

\section{Study area and fecal sample collection}

We conducted our study in a warm temperate evergreen broad-leaved forest around $150 \mathrm{~m}$ above sea level on the west coast of the island of Yakushima $\left(503 \mathrm{~km}^{2} ; 30^{\circ} \mathrm{N}, 130^{\circ} \mathrm{E}\right)$, southern Japan. The area is within a National Park, a Wildlife Special Protection Area, and a natural World Heritage site. The annual mean temperature is approximately $21^{\circ} \mathrm{C}$, which corresponds to the transition between subtropical and warm temperate zones (Tagawa 1994). Annual precipitation is approximately $2600 \mathrm{~mm}$ (Tagawa 1980). The vegetation of the study area consists mainly of secondary and primary forest dominated by evergreen species of Fagaceae, Myrsinaceae, and Lauraceae. Subtropical plants, such as 
Ficus superba, Ficus microcarpa, Trema orientalis, and Cyathea boninsimensis, are also present. Forest floor vegetation does not develop, possibly because of shading by evergreen trees and feeding pressure from deer (Tsujino and Yumoto 2004).

Deer in the study area were well habituated (Agetsuma et al. 2011) and researchers could follow them and observe their behavior at close quarters. On May 20, 2015, we followed three female deer and collected their fecal pellets just after defecation. Then, we collected fecal solutions from the three female deer as Day 0 samples. We rubbed the surface of a few fecal pellets of each deer using cotton swabs soaked with lyses buffer consisting of $0.5 \%$ SDS, 100 mM EDTA, 100mMTris- $\mathrm{HCl}$, and $10 \mathrm{mM} \mathrm{NaCl}$ (Hayaishi and Kawamoto 2006; Longmire et al. 1997). Then, we stirred the cotton swabs in 2-ml microtubes filled with $1 \mathrm{ml}$ of lyses buffer and kept the fecal solutions in the tubes. We divided the remaining fecal pellets from each deer into three portions, each of which was kept under one of the following environmental conditions: (1) Natural condition (on the forest floor under the forest canopy where the feces had been collected), (2) Exposed condition (on exposed ground without cover from rain or sunlight), and (3) Indoor condition (inside the laboratory, shaded from sunlight, at a temperature between 17 and $25^{\circ} \mathrm{C}$ and humidity of about 60\%). After 3, 5, and 10 days, we collected fecal solutions from fecal pellets under each condition using the procedure described above. All fecal solutions in 2-ml microtubes were then kept in the dark at ambient temperature until analysis. We also recorded the weather conditions on each day and the changes in the color and surface texture of the fecal pellets throughout the study period. Data on temperature and humidity during the study period were obtained from a weather station of the Japan Meteorological Agency, located about $25 \mathrm{~km}$ from the study site.

\section{DNA analysis}

We extracted DNA from fecal solutions using the QIAamp DNA stool Mini Kit (QIAGEN) on June 1, 2015. We amplified 15 microsatellite loci used in a previous genetic study on Japanese sika deer (Okada and Tamate 2000). For multiplex polymerase chain reaction (PCR), we modified several primers and prepared two primer sets (Table 1): set I (CSSM019, TGLA53, ETH225, Cervid14, CSSM043, BOVIRBP, and BM3628) and set II (OarFCB193, BM4107, BM203, RM188, BM888, BMC1009, BM6506, and BL42). We added the sequence GTTCTT to the 5' end of the reverse primers for complete adenylation of the $3^{\prime}$ end of the forward strand (Brownstein et al. 1996).

PCR amplifications were carried out in a total volume of $10 \mu \mathrm{l}$, containing $2 \mu \mathrm{l}$ template DNA, 5 $\mu \mathrm{l}$ PCR Master Mix (QIAGEN multiplex PCR Kit), and $0.2 \mu \mathrm{M}$ of each primer (forward primers were 
fluorescently labeled, Table 1). After initial incubation at $95{ }^{\circ} \mathrm{C}$ for $15 \mathrm{~min}, 45$ amplification cycles were performed with denaturation at $94{ }^{\circ} \mathrm{C}$ for $30 \mathrm{~s}$, annealing at $57{ }^{\circ} \mathrm{C}$ for $30 \mathrm{~s}$, and extension at $72{ }^{\circ} \mathrm{C}$ for 30 $\mathrm{s}$, followed by a final extension at $60{ }^{\circ} \mathrm{C}$ for $30 \mathrm{~min}$.

DNA fragment analyses were performed using an ABI3130xl Genetic Analyzer (Thermo Fisher Scientific), and fragment sizes were determined with Peak Scanner Software version 1.0 (Thermo Fisher Scientific).

\section{Data analysis}

DNA extracted from fecal samples can be degraded and present at a low concentration (Taberlet et al. 1996). To ensure accurate genotyping of each individual, we followed the rule proposed by Lampa et al. (2013): heterozygous and homozygous alleles are determined by at least three and two positive replicates, respectively. We conducted three PCR replicates for Day 0 samples using primer sets I and II and obtained identical genotypes among the three replicates for each individual, except for two probable allelic dropout cases (CSSM043 and RM188). In both cases, heterozygous alleles were confirmed by two positive PCRs. Thus, the genotypes of Day 0 samples were used as reference genotypes.

For other fecal solutions, we conducted a single PCR per sample. Subsequently, we checked a total of 405 microsatellite loci (15 loci $\times 3$ deer individuals $\times 3$ conditions $\times 3$ periods) for the correct genotype (CG), amplification failure (NA), and genotyping error (ER). We further classified ER into false allele (FA), which was an error of producing a spurious band, and allelic dropout (AD), which was an error of lacking one of two alleles in a heterozygous individual. Rates of CG and NA were calculated by dividing the numbers of observed CG and NA by the total number of analyzed loci. Rates of ER and FA were calculated by dividing the numbers of ER and FA by the total number of positive amplifications (PA). The AD rate was calculated as the number of $\mathrm{AD}$ divided by the total number of positive amplifications expected to be heterozygous genotypes based on the reference genotypes (Broquet and Petit 2004).

Statistical analyses were performed using the R statistical computing environment, version 3.2.0 (R Core Team 2015). To quantify the effects of time after defecation and environmental conditions on rates of $\mathrm{CG}$, NA, ER, FA, and $\mathrm{AD}$, we used generalized linear mixed models (GLMM). GLMMs were created using the "glmmadmb" function in the glmmADMB package of R (Skaug et al. 2014). For testing the rates of CG or NA, we set the number of loci with CG or NA in each individual deer as response variables and the log-transformed total number of loci analyzed (i.e., 15 loci) as an offset term. 
For the rates of ER or FA, we set the number of loci with ER or FA in each individual as response variables and the log-transformed number of PA as an offset term. For the AD rate, we set the number of loci with $\mathrm{AD}$ as response variable for each individual and the log-transformed number of positive amplified loci of heterozygous genotypes as an offset term. We applied the zero-inflation option for ER, FA, and AD in GLMM. Then, we set time lapsed (days) and environmental condition as explanatory variables (the Natural condition was the reference category), and deer ID as a random effect term on the intercept in the GLMM. We assumed that the response variables followed a negative binomial distribution with a log link function. We made models with all possible combinations of variables and calculated Akaike's Information Criterion (AICc) and Akaike weights of the models. We then selected the model with the lowest AICc.

Table 1 Microsatellite marker information, and number of alleles $(A)$ and heterozygosity $(\mathrm{Ho})$ in Yaku sika deer analyzed

\begin{tabular}{llccccc}
\hline \multicolumn{1}{c}{ Locus } & Dye & Multi & N & Range & $A$ & $H o$ \\
\hline CSSM019 & FAM & I & 3 & $154-162$ & 3 & 0.667 \\
TGLA53 & FAM & I & 3 & $182-195$ & 3 & 0.667 \\
ETH225 & HEX & I & 3 & $144-164$ & 3 & 0.667 \\
Cervid14 & HEX & I & 3 & $235-243$ & 3 & 0.333 \\
CSSM043 & HEX & I & 3 & $262-264$ & 2 & 0.667 \\
BOVIRBP & NED & I & 3 & 185 & 1 & 0.000 \\
BM3628 & NED & I & 3 & $208-216$ & 3 & 0.667 \\
OarFCB193 & FAM & II & 3 & $129-133$ & 3 & 0.667 \\
BM4107 & FAM & II & 3 & $166-174$ & 3 & 1.000 \\
BM203 & FAM & II & 3 & $223-233$ & 2 & 0.667 \\
RM188 & HEX & II & 3 & $148-160$ & 3 & 1.000 \\
BM888 & HEX & II & 3 & $204-210$ & 3 & 0.667 \\
BMC1009 & HEX & II & 3 & $286-294$ & 2 & 0.667 \\
BM6506 & NED & II & 3 & $203-220$ & 2 & 0.333 \\
BL42 & NED & II & 3 & $256-258$ & 2 & 0.333 \\
\hline Mean & & & & & 2.5 & 0.600 \\
\hline
\end{tabular}

Multi, set of multiplex PCR, $N$, number of deer individuals analyzed 


\section{Results}

The mean daily temperature during the study period (from May 20 to 31, 2015) was $21.3{ }^{\circ} \mathrm{C}$ (range 16 $27^{\circ} \mathrm{C}$ ), and the mean daily humidity was 76\% (range 56-89\%). It rained on Day 3, Day 8, and Day 10.

Among the 15 microsatellite loci analyzed in Day 0 samples, the mean number of alleles was

2.5, and the mean heterozygosity was 0.60 (Table 1). For samples from Day 3 to Day 10 under the three environmental conditions, the mean rates of PA, CG, and NA were 67.2, 60.2, and 32.8\%, respectively (Table 2).

Table 2 Rates (\%) of positive amplification $(P A)$, correct genotype (CG), and amplification failure (NA) in each locus

\begin{tabular}{|c|c|c|c|c|c|c|c|c|c|c|c|c|c|}
\hline \multirow{2}{*}{ Locus } & \multirow{2}{*}{$\mathrm{N}$} & \multicolumn{4}{|c|}{ PA rate } & \multicolumn{4}{|c|}{ CG rate } & \multicolumn{4}{|c|}{ NA rate } \\
\hline & & Day 3 & Day 5 & Day 10 & $n$ & Day 3 & Day 5 & Day 10 & $\mathrm{M}$ & ay 3 & Day 5 & Day 10 & Mean \\
\hline CSSM019 & 9 & 77.8 & 77.8 & 66.7 & 74.1 & 77.8 & 66.7 & 55.6 & 66.7 & 22.2 & 22.2 & 33.3 & 25.9 \\
\hline TGLA53 & 9 & 77.8 & 55.6 & 44.4 & 59.3 & 77.8 & 55.6 & 33.3 & 55.6 & 22.2 & 44.4 & 55.6 & 40.7 \\
\hline ETH225 & 9 & 88.9 & 77.8 & 33.3 & 66.7 & 77.8 & 55.6 & 33.3 & 55.6 & 11.1 & 22.2 & 66.7 & 33.3 \\
\hline Cervid14 & 9 & 77.8 & 55.6 & 33.3 & 55.6 & 77.8 & 55.6 & 33.3 & 55.6 & 22.2 & 44.4 & 66.7 & 44.4 \\
\hline CSSM043 & 9 & 77.8 & 44.4 & 33.3 & 51.9 & 77.8 & 33.3 & 33.3 & 48.1 & 22.2 & 55.6 & 66.7 & 48.1 \\
\hline BOVIRBP & 9 & 88.9 & 77.8 & 44.4 & 70.4 & 88.9 & 66.7 & 44.4 & 66.7 & 11.1 & 22.2 & 55.6 & 29.6 \\
\hline BM3628 & 9 & 88.9 & 66.7 & 44.4 & 66.7 & 77.8 & 55.6 & 33.3 & 55.6 & 11.1 & 33.3 & 55.6 & 33.3 \\
\hline OarFCB193 & 9 & 100.0 & 77.8 & 88.9 & 88.9 & 100.0 & 55.6 & 77.8 & 77.8 & 0.0 & 22.2 & 11.1 & 11.1 \\
\hline BM4107 & 9 & 100.0 & 55.6 & 55.6 & 70.4 & 100.0 & 44.4 & 33.3 & 59.3 & 0.0 & 44.4 & 44.4 & 29.6 \\
\hline BM203 & 9 & 100.0 & 88.9 & 55.6 & 81.5 & 88.9 & 44.4 & 55.6 & 63.0 & 0.0 & 11.1 & 44.4 & 18.5 \\
\hline RM188 & 9 & 100.0 & 66.7 & 44.4 & 70.4 & 77.8 & 44.4 & 33.3 & 51.9 & 0.0 & 33.3 & 55.6 & 29.6 \\
\hline BM888 & 9 & 100.0 & 33.3 & 33.3 & 55.6 & 100.0 & 33.3 & 33.3 & 55.6 & 0.0 & 66.7 & 66.7 & 44.4 \\
\hline BMC1009 & 9 & 100.0 & 44.4 & 44.4 & 63.0 & 100.0 & 44.4 & 44.4 & 63.0 & 0.0 & 55.6 & 55.6 & 37.0 \\
\hline BM6506 & 9 & 100.0 & 44.4 & 66.7 & 70.4 & 100.0 & 44.4 & 55.6 & 66.7 & 0.0 & 55.6 & 33.3 & 29.6 \\
\hline BL42 & 9 & 100.0 & 55.6 & 33.3 & 63.0 & 100.0 & 55.6 & 33.3 & 63.0 & 0.0 & 44.4 & 66.7 & 37.0 \\
\hline Mean & & 91.9 & 61.5 & 48.1 & 67.2 & 88.1 & 50.4 & 42.2 & 60.2 & 8.1 & 38.5 & 51.9 & 32.8 \\
\hline
\end{tabular}

$N$ number of samples analyzed

For the Indoor condition, the CG rate held at about 100\% (97.8-100\%) and the rates of NA, ER, FA, and AD were close to 0\% (0-3.7\%) throughout the study period (Fig. 1). For the Natural condition, the $\mathrm{CG}$ rate on Day 3 was $100 \%$ and the rates of $\mathrm{NA}, \mathrm{ER}, \mathrm{FA}$, and $\mathrm{AD}$ were $0 \%$. After that, the CG rate rapidly decreased and the rates of NA, ER, and AD increased. In the Exposed condition, DNA degradation progressed faster than that in the other two conditions (Fig. 1). 

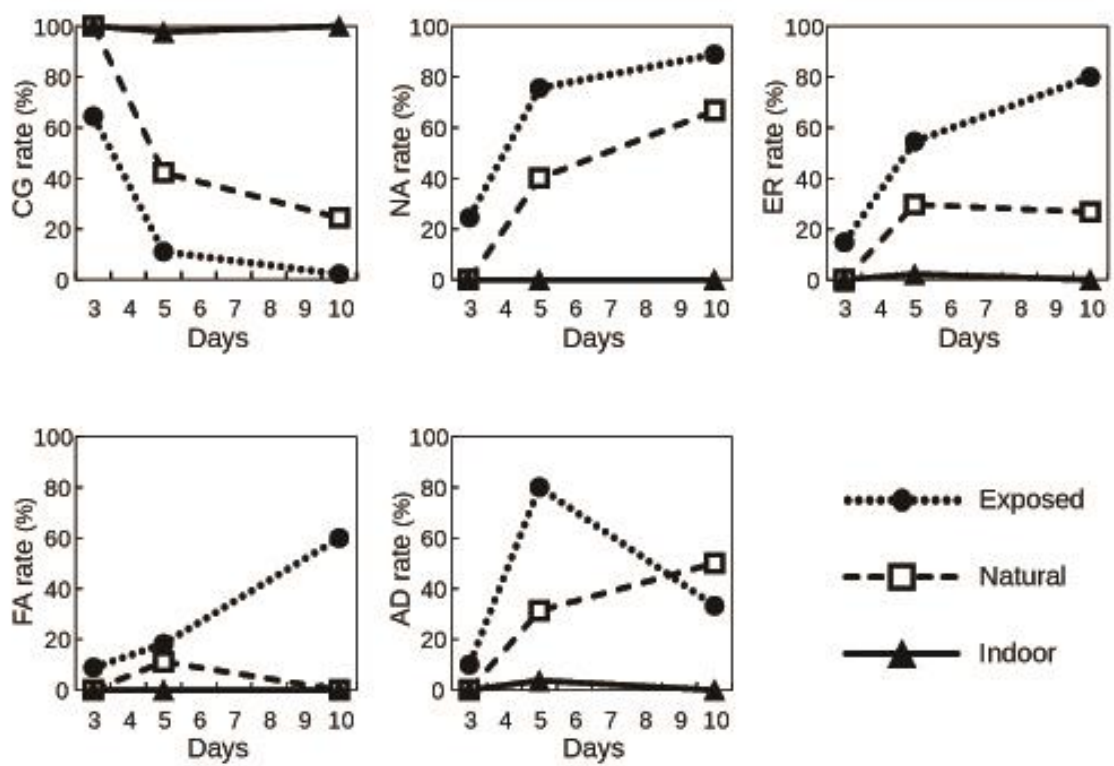

Fig. 1 Rates of correct genotype $(C G)$, amplification failure $(N A)$, genotyping error $(E R)$, false allele $(F A)$, and allelic dropout $(A D)$ over time in three different environments

The rates of CG, NA, ER, FA, and AD were significantly different between the three environmental conditions in which fecal pellets were placed (Table 3). The CG rates tended to be higher in the Indoor condition and lower in the Exposed condition than in the Natural condition. On the other hand, the rates of NA, ER, FA, and AD tended to be lower in the Indoor condition and higher in the Exposed condition than in the Natural condition. In addition, time after defecation had a highly significant negative effect on the CG rate and a positive effect on the NA and FA rates (Table 2).

Table 3 Selected models for rates of correct genotype $(C G)$, amplification failure $(N A)$, genotyping error $(E R)$, false allele $(F A)$, and allelic dropout $(A D)$

\begin{tabular}{|c|c|c|c|c|c|c|c|c|}
\hline Response variable & $\mathrm{N}$ & & Selec & ted model & & $\mathrm{Df}$ & AIC & Akaike weight \\
\hline CG & 27 & $-12.18 * * *$ & -0.13 lapse day**** & +0.71 Indoor $* *$ & -0.80 Exposed $* *$ & 6 & 165.7 & 0.989 \\
\hline NA & 27 & $-14.72 * * *$ & +0.20 lapse day*** & -25.68 Indoor & +0.71 Exposed* & 6 & 115.8 & 0.948 \\
\hline ER & 26 & $-5.30^{* * *}$ & & -12.27 Indoor*** & +2.28 Exposed & 6 & 112.5 & 0.615 \\
\hline FA & 26 & $-17.50^{* * *}$ & +0.90 lapse day*** & -20.74 Indoor & +5.85 Exposed $* * *$ & 7 & 64.6 & 0.694 \\
\hline $\mathrm{AD}$ & 25 & -0.67 & & -9.90 Indoor*** & +0.30 Exposed & 6 & 95.2 & 0.766 \\
\hline
\end{tabular}

For coefficients of conditions, the reference category was Natural condition, $N$ number of samples analyzed $* P<0.05, * * P<0.01, * * * P<0.001$ 
There was a highly significant positive correlation between the rates of ER and NA $(E R=0.733$ $\times$ NA-0.991, $r=0.94, N=9, P<0.001$, Fig. 2). Therefore, it is possible to predict the ER rate from the NA rate to some extent. The regression equation showed that when the NA rate was lower than $25 \%$, which corresponded to the NA rates of all conditions on Day 3 (Fig. 1), the ER rate was expected to be less than $18 \%$.

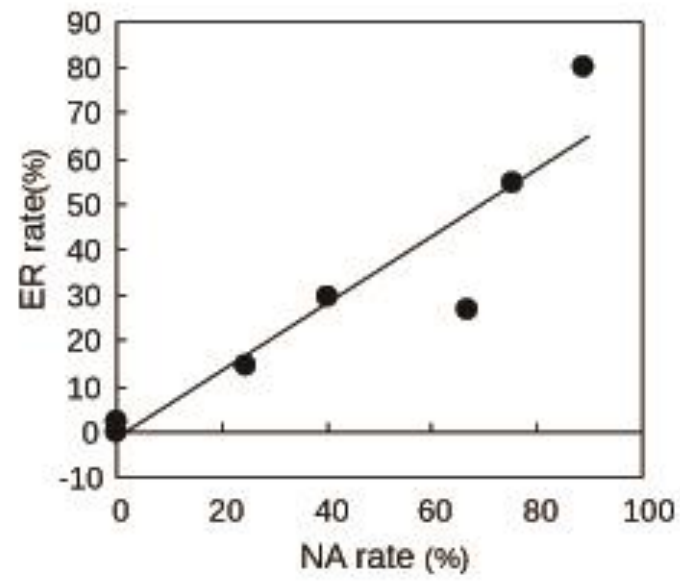

Fig. 2 Relation between rates of $N A$ and $E R$ with regression line $(E R=0.733 \times N A-0.991, \mathrm{r}=0.94, N=9, P<0.001)$

The surface texture of the fecal pellets changed over time and was influenced by the environmental condition. On Day 0, the surface was slightly wet and shiny dark brown. In the Indoor condition, the surface gradually became dry and the color changed from brown to black by Day 5. By Day 8, small cracks could be seen on the surface. In the Natural condition, the pellet surface was shiny blackish brown and dry until Day 2. However, after the small rain on Day 3, the surface appeared quite similar to what it had been on Day 0. On Day 5, the pellet surface was not noticeably different from that on Day 3, although parts of the pellets were broken. When we rubbed the surface of the pellets with cotton swabs to sample DNA, they collapsed. After the rain on Day 10, although there were no cracks on the surface, the pellets easily collapsed when picked up using tweezers. In the Exposed condition, the pellets were already dry and blackened by Day 1 . However, after the small rain on Day 3, the pellets became wet and dark brown and the appearance was quite similar to that on Day 0. On Day 5, the 
surface had become matte with reddish brown cracks, which increased with desiccation. However, after the rain on Day 10, the surface texture was once again similar to that on Day 0.

\section{Discussion}

This study provided information about the process of DNA degradation in feces of deer living in the warm temperate zone. Fecal pellets kept in the Indoor condition showed little evidence of DNA degradation. In general, DNA degradation increased with time after defecation in the Natural and Exposed conditions (Fig. 1 and Table 2). The only result that appeared to be an exception was the rate of AD for Day 10 samples, which was lower than that for Day 5 samples in the Exposed condition (Fig. 1). This was probably due to the low PCR success rate for those samples, which causes a small denominator. One notable finding was that the CG rate was $100 \%$ using feces left on the forest floor (Natural condition) for 3 days after defecation.

Rates of CG tended to be higher and those of NA, ER, FA, and AD tended to be lower in the Indoor condition than in the Natural condition. By contrast, rates of CG tended to be lower and those of NA, ER, FA, and AD tended to be higher in the Exposed condition than in the Natural condition (Table 3). Similarly, Brinkman et al. (2010) reported that for black tailed deer in the cool temperate zone rates of NA and ER remained low for feces kept in boxes. The temperature and humidity of the Indoor condition were not very different from those of the Natural condition, which suggest that these factors may not affect DNA degradation in this study. It is difficult to judge whether rain or other factors, such as sunlight, were responsible for increasing the rate of DNA degradation. However, rain may be a major factor, as suggested by Wedrowicz et al. (2013), because the CG rate decreased rapidly under Natural and Exposed conditions after the first rain on Day 3. Removal of water is one of the essential approaches to preventing activation of nuclease when sampling feces (Beja-Pereira et al. 2009). Therefore, it is reasonable to think that DNA degradation accelerates after rain.

We should pay particular attention to the rates of ER (FA and AD), because FA and AD lead to inaccurate results, while NA just decreases the efficiency of genetic analyses. However, in some situations, it is difficult to calculate rates of FA and AD using non-invasive samples, because the number of PCR replicates required is different according to PCR error rates (Morin et al. 2001). In this study, we showed that we can assess the quality of fecal DNA samples to some extent by using the NA rate, as it was highly correlated with the ER rate (Fig. 2). DNA samples with an NA rate of less than $25 \%$ were 
expected to have an ER rate of less than $18 \%$ in this study. When we used $18 \%$ ER, the probability that all three consecutive PCRs yield false genotypes was 0.006 (i.e., 0.183). Therefore, if three PCR replicates yield the same genotype, the genotype is highly reliable. Feces of Day 3 under all environmental conditions in this study were suitable for genetic analyses, because all had ER rates lower than 15\% (Fig. 1). Therefore, collecting feces within 3 days of defecation may be important for reliable genotyping, although rain might have a negative effect on correct genotyping.

This study showed that the fecal surface appearance was also affected by rainfall. Rain produced a recovery in the apparent freshness of the surface texture of fecal pellets. Without the effect of rainfall (Indoor condition), we found a gradual change in color and an increasing dryness of the feces. In addition, our data suggested that surface cracks might be regarded as a marker of DNA degradation in the field.

Based on the results of this study, we propose a number of recommendations for the selection of deer feces for efficient genetic analyses in the warm temperate zone. In cases where a repeatable routine census is possible, we recommend sampling feces at an interval of 3 days or less. The majority of the fecal pellets collected would then be recent enough to yield reliable genotypes regardless of environmental conditions. In cases where routine census is not possible, we recommend sampling when there has been no rainfall for several days before. As far as possible, selection of fecal pellets should be based on the absence of cracks and if the pellet can be picked up without collapsing by using tweezers; further, sites that are under the cover of trees should be prioritized. After PCR and genotyping, the fecal samples can then be screened to show which of them can yield reliable genotyping for further analyses by using the NA rate (as an indicator of ER rate).

The use of non-invasive sampling for genetic analyses has increased in various fields, including socio-ecological research such as estimation of population sizes and the effect of kinship on behavior (e.g., Bellemain et al. 2005; Inoue et al. 2008, 2013; Lampa et al. 2013). In the future, the application of non-invasive sampling for genetic analyses is likely to expand to include additional fields of study because of its usefulness (Kohn and Wayne 1997). To complement this research, there is a need for much more information about species-specific and habitat-specific designs for fecal sampling to minimize the influence of DNA degradation (Lampa et al. 2013). Our proposed recommendations could serve as a useful point of reference, not only for sika deer in a warm temperate forest, but also for other even-toed ungulates in various forest ecosystems. 
Acknowledgments Funding was provided by the Leading Graduate Program in Primatology and Wildlife Science, Kyoto University, Japan, as part of the Resilience and Adaptation Program. We thank participants of the programs: B. Z. Katale, E. L. Baking, H. Koba, K. Ichiyama, N. Tajima, and T. Ohkawa for analyses; Dr. H. Sugiura, Dr. K. Agata, Dr. T. Matsuzawa, H. Tajima, K. Yokoyama, and other staff of Kyoto University for supporting this research. We are grateful to the Ministry of the Environment, the Yakushima Forest Environment Conservation Center, and Kagoshima Prefecture for permitting us to conduct this research.

\section{References}

Agetsuma N, Agetsuma-Yanagihara Y, Hino T (2011) Food habits of Japanese deer in an evergreen forest: litter-feeding deer. Mamm Biol 76:201-207

Akomo-Okoue EF, Inoue E, Atteke C, Nakashima Y, Hongo S, Inoue-Murayama M, Yamagiwa J (2015) Noninvasive genetic analysis for assessing the abundance of duiker species among habitats in the tropical forest of Moukalaba, Gabon. Mammal Research 60:375-384

Barbosa MA, Carranza J (2010) Lack of geographic variation in Y-chromosomal introns of red deer (Cervus elaphus). Journal of Negative Results 7:1-4

Beja-Pereira A, Oliveira R, Alves PC, Schwartz MK, Luikart G (2009) Advancing ecological understandings through technological transformations in noninvasive genetics. Mol Ecol Resour 9:1279-1301

Bellemain E, Swenson JE, Tallmon D, Brunberg S, Taberlet P (2005) Estimating population size of elusive animals with DNA from hunter-collected feces: four methods for brown bears. Conserv Biol 19:150-161

Brinkman TJ, Schwartz MK, Person DK, Pilgrim KL, Hundertmark KJ (2010) Effects of time and rainfall on PCR success using DNA extracted from deer fecal pellets. Conserv Genet 11:15471552

Broquet T, Petit E (2004) Quantifying genotyping errors in noninvasive population genetics. Mol Ecol $13: 3601-3608$

Brownstein MJ, Carpten JD, Smith JR (1996) Modulation of non-templated nucleotide addition by Taq DNA polymerase: primer modifications that facilitate genotyping. Bio Techniques 20:1004-1006

DeMay SM, Becker PA, Eidson CA, Rachlow JL, Johnson TR, Waits LP (2013) Evaluating DNA degradation rates in faecal pellets of the endangered pygmy rabbit. Mol Ecol Res 13:654-662 
Flagstad O, Roed K, Stacy JE, Jakobsen KS (1999) Reliable noninvasive genotyping based on excremental PCR of nuclear DNA purified with a magnetic bead protocol. Mol Ecol 8:879-883

Hajkova P, Zemanova B, Bryja J, Hajek B, Roche K, Tkadlec E, Zima J (2006) Factors affecting success of PCR amplification of microsatellite loci from otter faeces. Mol Ecol Notes 6:559-562

Hayaishi S, Kawamoto Y (2006) Low genetic diversity and biased distribution of mitochondrial DNA haplotypes in the Japanese macaque (Macaca fuscata yakui) on Yakushima Island. Primates 47:158-164

Henry-Roitberg C (2008) The phylogeography of red deer (Cervus elaphus) in Exmoor National Park. University of Edinburgh, Edinburgh

Inoue E (2015) DNA analysis using noninvasive samples: methods of sample collection, DNA extraction, PCR amplification and kinship analysis. Primate Research 31:3-18 (in Japanese)

Inoue E, Akomo-Okoue EF, Ando C, Iwata Y, Judai M, Fujita S, Hongo S, Nze-Nkogue C, InoueMurayama M, Yamagiwa J (2013) Male genetic structure and paternity in western lowland gorillas (Gorilla gorilla gorilla). Am J Phys Anthropol 151:583-588

Inoue E, Inoue-Murayama M, Vigilant L, Takenaka O, Nishida T (2008) Relatedness in wild chimpanzees: influence of paternity, male philopatry, and demographic factors. Am J Phys Anthropol 137:256-262

Kohn MH, Wayne RK (1997) Facts from feces revisited. Trends Ecol Evol 12:223-227

Lampa S, Henle K, Klenke R, Hoehn M, Gruber B (2013) How to overcome genotyping errors in noninvasive genetic mark-recapture population size estimation - a review of available methods illustrated by a case study. J Wildl Manag 77:1490-1511

Longmire JL, Maltbie M, Baker RJ (1997) Use of "lysis buffer" in DNA isolation and its implication for museum collections. Museum of Texas Tech University, Lubbock

Lucchini V, Fabbri E, Marucco F, Ricci S, Boitani L, Randi E (2002) Noninvasive molecular tracking of colonizing wolf (Canis lupus) packs in the western Italian Alps. Mol Ecol 11:857-868

Morin PA, Chambers KE, Boesch C, Vigilant L (2001) Quantitative polymerase chain reaction analysis of DNA from noninvasive samples for accurate microsatellite genotyping of wild chimpanzees (Pan troglodytes versus). Mol Ecol 10:1835-1844

Murphy MA, Kendall KC, Robinson A, Waits LP (2007) The impact of time and field conditions on brown bear (Ursus arctos) faecal DNA amplification. Conserv Genet 8:1219-1224 
Okada A, Tamate HB (2000) Pedigree analysis of the sika deer (Cervus nippon) using microsatellite markers. Zool Sci 17:335-340

Pérez-Espona S, Pérez-Barbería FJ, Goodall-Copestake WP, Jiggins CD, Gordon IJ, Pemberton JM (2009) Genetic diversity and population structure of Scottish Highland red deer (Cervus elaphus) populations: a mitochondrial survey. Heredity 102:199-210

Piggott MP (2004) Effect of sample age and season of collection on the reliability of microsatellite genotyping of faecal DNA. Wildl Res 31:485-493

R Core Team (2015) R: a language and environment for statistical computing (ver3.2.0). R Foundation for Statistical Computing, Vienna

Renan S, Speyer E, Shahar N, Gueta T, Templeton AR, Bar-David S (2012) A factorial design experiment as a pilot study for noninvasive genetic sampling. Mol Ecol Resour 12:1040-1047

Schettler E, Steinbach F, Eschenbacher-Kaps I, Gerst K, Meussdoerffer F, Risch K, Streich WJ, Frölich K (2006) Surveillance for prion disease in Cervids, Germany. Emerg Infect Dis 12:319-322

Skaug H, Fournier D, Bolker B, Magnusson A, Nielsen A (2014) Generalized linear mixed models using AD model builder. Version 0.8.0. http://glmmadmb.r-forge.r-project.org. Accessed 23 May 2014

Taberlet P, Griffin S, Goossens B, Questiau S, Manceau V, Escaravage N, Waits LP, Bouvet J (1996) Reliable genotyping of samples with very low DNA quantities using PCR. Nucleic Acids Res 24:3189-3194

Tagawa H (1980) Vegetation on the western slope of Mt. Kuniwaridake, Yakushima Island. Science Reports of Kagoshima University 29: 121-137 (in Japanese)

Tagawa H (1994) Natural World Heritage, Yakushima. Japan Broadcast Publishing, Tokyo (in Japanese)

Tamate HB, Okada A, Minami M, Ohnishi N, Higuchi H, Takatsuki S (2000) Genetic variations revealed by microsatellite markers in a small population of the sika deer (Cervus nippon) on Kinkazan Island, northern Japan. Zool Sci 17:47-53

Tamate HB, Tatsuzawa S, Suda K, Izawa M, Doi T, Sunagawa K, Miyahira F, Tado H (1998) Mitochondrial DNA variations in local populations of the Japanese sika deer, Cervus nippon. $\mathrm{J}$ Mammal 79:1396-1403

Tsujino R, Yumoto T (2004) Effects of sika deer on tree seedlings in a warm temperate forest on Yakushima Island, Japan. Ecol Res 19:291-300 
Wedrowicz F, Karsa M, Mosse J, Hogan FE (2013) Reliable genotyping of the koala (Phascolarctos cinereus) using DNA isolated from a single faecal pellet. Mol Ecol Resour 13:634-641

Wehausen JD, Ramey RR, Epps CW (2004) Experiments in DNA extraction and PCR amplification from bighorn sheep feces: the importance of DNA extraction method. J Hered 95:503-509

Whitehead GK (1993) Whitehead encyclopedia of deer. Swan Hill Press, Shrewsbury

Woodruff SP, Johnson TR, Waits LP (2015) Evaluating the interaction of faecal pellet deposition rates and DNA degradation rates to optimize sampling design for DNA-based mark-recapture analysis of Sonoran pronghorn. Mol Ecol Resour 15:843-854

Yamada M, Hosoi E, Nagata J, Tamate HB, Tado H (2007) Phylogenetic relationship of the southern Japan lineages of the sika deer (Cervus nippon) in Shikoku and Kyushu Islands, Japan. Mammal Study 32:121-127

Yuasa T (2007) Genetic structure and gene flow between the Japanese sika deer populations in Tanzawa Mountains and Mt. Fuji area. In: Institution of scientific investigation on Tanzawa-Oyama (ed) Reports of scientific investigation on Tanzawa-Oyama. Hiraoka Environmental Science Laboratory, Sagamihara, pp146-152 (in Japanese)

Yuasa T, Nagata J, Hamasaki S, Tsuruga H, Furubayashi K (2007) The impact of habitat fragmentation on genetic structure of the Japanese sika deer (Cervus nippon) in southern Kantoh, revealed by mitochondrial D-loop sequences. Ecol Res 22:97-106 